\title{
DESENVOLVIMENTO TERRITORIAL E CAPITAL SOCIAL EM ACORDOS DE PESCA NA AMAZÔNIA ORIENTAL1
}

Valcir Bispo Santos ${ }^{2}$

\section{Introdução}

O foco deste artigo é analisar os "acordos de pesca" praticados por comunidades ribeirinhas da Amazônia Oriental nas ilhas do município de Cametá, na região do Baixo Tocantins - nordeste do estado do Pará, no estuário da bacia do rio Amazonas - tendo em vista, sobretudo, a sua dinâmica interna e os recursos endógenos que articula e mobiliza. Os "acordos de pesca" podem ser definidos sinteticamente enquanto formas de arranjos institucionais praticados por comunidades ribeirinhas com a finalidade de manejar recursos pesqueiros, mas que se notabilizam pelas práticas de inovação no que tange à mobilização de recursos do capital social. Desta forma, pretende-se interpretar as práticas dos acordos de pesca do Baixo Tocantins, a partir de uma abordagem situada no campo institucionalista da teoria econômica.

As chamadas abordagens institucionalistas objetivam, de forma geral, estudar o papel das instituições, normas, valores, regras e culturas que organizam as interações econômicas, sociais e políticas na sociedade. Os indivíduos, ao se relacionarem coletivamente, seguem determinadas regras; suas ações, lutas e conflitos transcorrem no mundo das instituições, as quais restringem as escolhas egoístas e maximizadoras dos atores sociais envolvidos. Tais premissas se contrapõem ao individualismo metodológico seguido pela abordagem convencional neoclássica, hegemônica no campo das teorias econômicas.

Os principais protagonistas dos acordos de pesca praticados no Baixo Tocantins são os produtores agroextrativistas ribeirinhos e as famílias e comunidades pesqueiras que organizam tais arranjos institucionais. Cumpre ressaltar a atuação de outros segmentos sociais organizados que assumem papeis relevantes, na função de mediadores e dinamizadores dos acordos de pesca na região do Baixo Tocantins. Nesta perspectiva, destacam-se as colônias de pescadores. Para alguns pesquisadores e observadores da cena política regional, a Colônia Z-16, de Cametá, se constitui na mais influente organização social da região do Baixo Tocantins, tendo dentre as suas principais linhas de atuação, o estímulo à organização e à difusão dos acordos de pesca. Outro segmento social de relevo é a Prelazia da Igreja Católica em Cametá, destacando-se sobretudo as Comunidades Eclesiais de Base (CEBs), cuja atuação histórica vem sendo determinante na formação política e organizacional dos movimentos sociais do Baixo Tocantins, sobretudo de

\footnotetext{
${ }^{1}$ Artigo baseado em Tese de Doutorado defendida pelo autor no Instituto de Planejamento Urbano e Regional da Universidade Federal do Rio de Janeiro - IPPUR/UFRJ

${ }^{2}$ Professor Doutor da Faculdade de Economia da Universidade Federal do Pará - UFPA; e-mail: valcirsantos@uol.com.br
} 
pescadores e produtores agroextrativistas ribeirinhos. Além disso, a crença e fé cristãs partilhadas por famílias de várias comunidades são importantes componentes de coesão social.

A hipótese base da pesquisa é a de que as iniciativas consideradas exitosas em termos de acordos de pesca possuem relação direta com as trajetórias de evolução institucional (path dependency) e territorial das comunidades ribeirinhas pesquisadas. A metodologia da pesquisa teve como base a realização de entrevistas semiestruturadas junto a pescadores, produtores e lideranças ribeirinhas; gestores e funcionários públicos, bem como políticos locais. Grande parte das entrevistas foi realizada no período de setembro de 2004 a julho de 2005, sendo complementada por outras entrevistas em meados de 2013, abrangendo pouco mais de trinta pessoas, sobretudo nas ilhas de Cametá. Com base nas suas diferentes trajetórias de evolução institucional, foram selecionadas três comunidades ribeirinhas (ou ilhas) de Cametá: Jaracuera Grande, Pacuí e Cuxipiari Carmo.

Este artigo está estruturado em cinco partes, incluindo esta Introdução. Na segunda parte, faz-se uma síntese do corpo teórico institucionalista e dos principais conceitos e noções utilizados nesse artigo, tais como desenvolvimento territorial e endógeno, formas intermediárias de coordenação econômica, capital social, redes.

A terceira parte apresenta uma síntese acerca da região do Baixo Tocantins, sobretudo da realidade social, política e econômica das ilhas e várzeas de Cametá, com destaque para os impactos negativos para a economia ribeirinha decorrentes da implantação da hidrelétrica de Tucuruí.

A quarta parte realiza um diagnóstico dos acordos de pesca, a partir das entrevistas e observações durante a pesquisa de campo realizada nas ilhas de Cametá. Destarte, observa-se que as práticas, normas e motivações inerentes aos acordos de pesca variam conforme as especificidades históricas e institucionais de cada região. No entanto, além da hipótese base, outros fatores surgiram como força explicativa, sobretudo para elucidar as motivações dos produtores agroextrativistas e pescadores artesanais ao longo do processo de consolidação dos acordos de pesca.

A quinta e última parte apresenta um balanço sobre os acordos de pesca do ponto vista institucional. Em suma, propõe como consideração final que as práticas de gestão sustentável dos recursos pesqueiros e vegetais vigentes no Baixo Tocantins encontram-se ancoradas em normas e valores socioculturais partilhados pelas comunidades ribeirinhas. 


\section{A concepção institucionalista de desenvolvimento territorial: formas intermediárias de coordenação, redes e capital social}

Para compreender melhor a concepção institucionalista de desenvolvimento endógeno ou territorial, segundo Muls (2008), é necessário enfatizar no que ela se diferencia das teorias tradicionais de crescimento econômico e de políticas regionais, que, consequentemente, consideram o Estado e o Mercado como as duas formas privilegiadas de coordenação da economia. Na tradição da literatura econômica, desde Adam Smith, o pensamento liberal e a tese da "mão invisível" (do mercado) sempre se notabilizaram por defender o mercado enquanto forma de regulação (ou auto regulação) e coordenação das atividades e interações econômicas. Por outro lado, a concepção keynesiana (ou intervencionista) advoga a participação do Estado na regulação - ou em boa parte da coordenação das interações econômicas, embora dividindo-a com o mercado, segundo a chamada "síntese neoclássica", gerando o que alguns denominam como "economia mista", que prevaleceu em muitos países capitalistas após a II guerra mundial. As correntes marxistas de cunho ortodoxo, referenciando-se, sobretudo, em leituras de Lenin, Trotsky e outros teóricos socialistas, defendem que o Estado seja o regulador (ou a instância de coordenação) por excelência das atividades e interações econômicas, baseando-se na crítica de que a regulação pela via do mercado, no sistema capitalista, tende a gerar o caos no longo prazo.

Diferenciando-se da ortodoxia vigente em tais concepções tradicionais da literatura econômica, a concepção institucionalista leva em conta as formas intermediárias de coordenação, que são todos os organismos e instituições locais cuja atuação possui uma finalidade produtiva ou de regulação social em um determinado território, como o seu tecido empresarial, o poder público local e as representações da sociedade civil. Ou seja, o que a perspectiva institucionalista de desenvolvimento endógeno sinaliza é que há outras formas de coordenação econômica além do Mercado e do Estado, e que têm emergido como promotoras do desenvolvimento local, como: a "mobilização dos atores locais, a formação de redes ente organismos e instituições locais e uma maior cooperação entre empresas situadas em um mesmo território" (Mulls, 2008).

A questão central para o desenvolvimento passa a ser como articular estas três formas intermediárias de coordenação juntamente com as duas formas que foram (ou são) dominantes, que são o Estado e o Mercado. Cabe lembrar que a problemática sobre coordenação econômica se apresenta atualmente como um dos temas centrais das pesquisas no campo econômico, pois toda a atividade econômica encontra-se fundamentada na necessidade pragmática de coordenar as interações econômicas (ou ações econômicas) efetuadas pelos diferentes agentes econômicos entre si.

Nesta perspectiva teórica das estratégias de desenvolvimento endógeno e institucional, 0 papel do Estado seria o de constituir uma ordem jurídica e econômica que sinalizasse para os 
demais agentes sociais a primazia de padrões de organização de relações sociais fundadas em redes horizontais ou redes de parceria e de modos democráticos de regulação de conflitos. $A$ abordagem institucionalista incorpora elementos sociais e históricos que estão arraigados no território, presos aos costumes, à cultura e à tradição de uma região, incorporando, portanto, nas teorias do desenvolvimento, a contribuição de outras áreas do saber (Muls, 2008).

O Território desponta como sujeito da ação coletiva em prol do desenvolvimento econômico local (ou endógeno), através de seus organismos e instituições. A endogeneização do papel do território significa dizer que cada grupo de instituições e de organismos locais responsáveis por arranjos institucionais bem sucedidos é específico ao território. Os territórios são um construto socioeconômico e institucional. Em termos teóricos, a consideração do território como ator ou sujeito que se define por meio da ação coletiva e da construção de instituições locais, significa confrontar as leis de funcionamento de uma economia global às estratégias infranacionais que surgem como resposta ou reação aos imperativos da competição internacional (Muls, 2008).

A concepção de território, por sua vez, é largamente utilizada em estudos geográficos, sendo que Milton Santos a considera uma extensão do espaço apropriado e usado (Santos \& Silveira, 2003). Neste caso, remete-se a processos de "territorialização", ou seja, de formas ou processos de apropriação do espaço nas diferentes regiões, assim como as suas consequências, como a privatização e corporativização do território. Tais processos provocam, por sua vez, diferentes formas de "desterritorialização", como, por exemplo, a desapropriação de agricultores e pescadores ribeirinhos em função da construção de uma barragem, tal como ocorreu com a UHE de Tucuruí. Em outro sentido, "reterritorialização" é o processo de assentamento dos desterritorializados, dandoIhes novamente o sentido de apropriação de algo que perderam ou nunca tiveram (Dallabrida \& Becker, 2008).

Milton Santos (2003) alerta que as desigualdades regionais ou territoriais tendem a se acentuar, na medida em que as grandes empresas influenciam, com a sua lógica de valoração, outras empresas e o comportamento do poder público, fazendo com que o território se constitua em um "território corporativo". Ou seja, com a globalização, tende-se a confundir a lógica do mercado global com a lógica individual das empresas candidatas a permanecer ou se instalar em dada região, exigindo a adoção de um conjunto de medidas que acabam assumindo um papel de condução da política econômica e social (Santos \& Silveira, 2003).

As dinâmicas territoriais, no entanto, vêm perturbar a regulação pela pressão heterônoma, e se apresentam sob a forma de reações autônomas. A abordagem em torno das dinâmicas territoriais de desenvolvimento ou da dinâmica endógena dos territórios passa a enfatizar as dinâmicas organizacionais das empresas e das redes atuantes no território na criação de recursos 
endógenos, bem como as interações entre as empresas, e destas com os demais atores institucionais do desenvolvimento (Dallabrida \& Becker, 2008). Dessa forma, as abordagens contemporâneas de desenvolvimento endógeno ou territorial consideram o território não mais como mero suporte passivo de recursos, mas como gerador de novos recursos, através de complexas formas organizacionais de gênese local, propiciadoras de múltiplas interações entre os atores locais, bem como com outros atores extralocais.

A reação autônoma (do território) será mensurada pela capacidade dos atores que vivem neste território em desviar o movimento imposto pela pressão heterônoma (isto é, da globalização e dos imperativos da competição internacional) e de redirecioná-lo positivamente para a criação consciente de valores adicionados (recursos específicos) localmente, ou seja, para a valoração de recursos ou produtos endógenos.

O capital social é a base sobre a qual se instauram as formas de manifestação da reação autônoma que, por sua vez, se expressam através da construção de redes. A densidade de capital social em um território é medida pela quantidade de redes duráveis e coesas de relações econômicas, sociais e institucionais entre os atores locais, as quais são institucionalizadas enquanto formas intermediárias de coordenação econômica. A densidade das redes que se estabelecem entre o poder público local, as firmas e a sociedade civil e, principalmente, a qualidade das redes entre essas formas intermediárias de coordenação fornece uma medida do estoque de capital social existente em um determinado território.

O conceito de capital social foi popularizado através dos trabalhos de Robert Putnam (1993) sobre as regiões da Itália. Putnam relacionou o desempenho econômico e institucional entre o centro-norte e o sul da Itália com suas tradições cívicas e sua dotação de "capital social", definidas como as "características da organização social, como confiança, normas e sistemas que contribuem para aumentar a eficiência da sociedade, facilitando as ações coordenadas".

Para Putnam, o capital social pode ser distinguido por dois componentes: (1) quando 0 capital social se refere estritamente aos laços no âmbito de um grupo ou comunidade, conhecido como "bonding capital social"; (2) quando se refere aos laços entre grupos heterogêneos ou inclusivos, conhecido como "bridging capital social". Michael Storper (2003) ressalta que bonding, em outras palavras, é uma versão operativa de "comunidade", enquanto bridging se refere à "sociedade". Na interpretação de Putnam, o aumento do voluntariado e do compromisso cívico é mais forte onde se dá uma abundância de bonding ou pertencimento a grupos. Porém, este pertencimento seria mais forte em sociedades mais homogêneas. 
Na visão de Storper (2003) esta interpretação de Putnam sobre capital social apresenta duas sérias limitações: (1) Putnam só considera que existe capital social onde ocorre uma abundância de bonding, ou seja, de comunidade, pois não considera relevante as pontes entre os grupos sociais (bridging); (2) a própria concepção de comunidade de Putnam seria demasiado restrita, pois ele só considera que possuem capital social os grupos que têm procedência cultural comum, baseada em laços históricos.

A institucionalização de relações sociais que já carregam em sua estrutura formas latentes e menos desenvolvidas de capital social é uma das principais tarefas na promoção do desenvolvimento endógeno (ou local). Como o capital social é intrínseco às relações sociais e, ao mesmo tempo, um produto da institucionalização dessas relações, a transição de suas formas latentes para formas mais maduras e institucionalizadas pode fomentar o desenvolvimento de um determinado território,

Em seu estudo sobre práticas de desenvolvimento no município de Pintadas, na região do semiárido baiano, Nordeste do Brasil, Carlos Milani (2003) buscou significados e expressões sociopolíticas e econômicas para uma definição crítica e analítica de capital social. Para Milani, 0 "desenvolvimento local pode se tornar ferramenta de análise mais dinâmica quando posto em relação com as lógicas de desigualdade", ou seja, quando associado à hipótese de que as dinâmicas geradoras de desigualdade e exclusão não podem ser desconstruídas exclusivamente pelo alto. $\mathrm{Na}$ visão de Milani (2003), o desenvolvimento local pode ser considerado como o conjunto de atividades culturais, econômicas, políticas e sociais que "participam de um projeto de transformação consciente da realidade local". É fundamental pensar o desenvolvimento local enquanto projeto integrado ao mercado, mas não somente: "o desenvolvimento local é também fruto de relações de conflito, competição, cooperação e reciprocidade entre atores", interesses e projetos de natureza social, política e cultural. A crise pela qual passa a teoria do desenvolvimento, em sua versão economicista, coincide com a crise do Estado, que passa a ser denunciado por sua inépcia, falta de transparência, ineficiência e corrupção, fazendo com que alguns associem apressadamente ambas as crises (Milani, 2003). Amartya Sen (1999) lembra que é fundamental ampliar a capacidade de realização das atividades livremente escolhidas e valorizadas por cada sujeito do desenvolvimento. Portanto, 0 desenvolvimento não é consequência automática do crescimento econômico (Sen, 1999).

Por outro lado, uma questão que adquiriu relevância trata da transformação e modernização das estruturas tradicionais de manejo dos recursos naturais de uso comum. É um debate contemporâneo, que encontra bastante ressonância nas experiências de gestão participativa ou compartilhada dos recursos pesqueiros proporcionadas pelos acordos de pesca. 
Uma contribuição fundamental neste debate foi de Elinor Ostrom (1933-2012) - a primeira mulher a receber um prêmio Nobel de Economia em 2009.

As contribuições de Ostrom ajudaram a reavaliar o dilema da "tragédia dos comuns". Este dilema é baseado na clássica formulação de Hardin (1968 apud OSTROM, 1990), de que as terras e pastos em propriedade comum estariam condenados a um uso excessivo e a um esgotamento se não fosse realizada a sua privatização e gestão pelo mercado de troca. Adotando uma perspectiva institucionalista (referenciada, sobretudo, nas contribuições teóricas da nova economia institucional-NEI), Ostrom rebateu a tese da "tragédia dos comuns", ao demonstrar que a transferência da gestão dos bens comuns para organizações de produtores ou de usuários pode se constituir em uma alternativa viável, sobretudo após a implementação de programas de descentralização da sua governança (OSTROM, 1990, 2008).

Na verdade, o que Ostrom propõe, de forma mais ampla, é uma análise da construção social de instituições locais adaptadas à gestão de recursos de propriedade comum, no quadro de uma cooperação fundada em escolhas e comportamentos coletivos. Por outro lado, coloca a norma da reciprocidade no centro desses dispositivos. Ou seja, Ostrom incorporou a temática de relações baseadas em confiança, reciprocidade e capital social para demonstrar a eficácia da ação coletiva nas formas de gestão coletiva de bens de uso comum (OSTROM, 2008).

Para Ostrom (2008), não há cooperação sem reciprocidade, ou seja, sem retorno ou sem compartilhamento por parte dos usuários. Os atores se esforçam para identificar os outros atores envolvidos e os consideram como possíveis cooperadores. Cooperam, a priori, com aqueles que manifestam tal intenção, e se recusam a cooperar se não houver reciprocidade. Existem sanções para aqueles que traem a confiança dos outros (OSTROM, 2008). Para a autora, é a confiança mútua que explica a reciprocidade, considerada como uma norma moral internalizada, ou como um princípio de troca social caracterizado pela vontade de cooperar.

No entanto, Ostrom também foi criticada, sobretudo por buscar a origem dos comportamentos de reciprocidade a partir de explicações biológicas, e não nas estruturas sociais, tal como postula a teoria da reciprocidade, que se baseia, por sua vez, em estudos antropológicos e na fenomenologia (SABOURIN, 2010).

Um "ponto da discórdia" importante se deu em função de Ostrom tratar a confiança, reciprocidade e reputação como normas sociais que são atributos dos usuários ou dos grupos de usuários (OSTROM, 2008). Mas para a teoria da reciprocidade, a confiança e a reputação são valores éticos, na medida em que correspondem ao reconhecimento público dos valores do outro, enquanto a reciprocidade é o nome de todas as estruturas de produção dos valores éticos. $A$ 
principal diferença é que, para a teoria da reciprocidade, a confiança e a reputação (o prestígio) são valores éticos produzidos pelas relações de reciprocidade simétrica (SABOURIN, 2010).

\section{Aspectos históricos da região do Baixo Tocantins e as mudanças decorrentes da implantação da Hidrelétrica de Tucuruí}

A sub-região do Baixo Tocantins localiza-se na região estuarina do rio Amazonas, e concentra a maior influência hidrográfica do rio Amazonas, que se manifesta nos parâmetros climáticos, na formação e no uso do solo, no tipo de vegetação e no manejo da floresta, assim como nas atividades humanas ali desenvolvidas. As marés possivelmente são a feição mais importante na porção do estuário do rio Amazonas. Com movimentos cíclicos a cada seis horas, as marés desse "mar" fluvial comandam o estilo de vida da população do estuário do rio Amazonas: regulam a navegação e o comércio, influenciam os hábitos de vida dos ribeirinhos, determinandoIhes o horário de acordar e de pescar, facilitam aos extratores florestais a retirada dos produtos dos centros de coleta, além de servirem de reserva e abastecimento alimentar (Costa, 2003).

A região do Baixo Tocantins é uma zona de colonização antiga, que data do século XVII, ainda no período colonial. O campesinato dessa região é possivelmente um dos primeiros a se estabelecer no Brasil, fruto da política colonial portuguesa de descimentos e fortins, que visava defender esta região considerada extremamente inóspita, e barrar o trânsito de outras nações europeias, sobretudo franceses, ingleses e holandeses, que já navegavam por estas porções territoriais. Além disso, o campesinato dessa região tem uma participação ativa em movimentos sociais, inclusive com marcos históricos importantes, como a participação no movimento insurrecional e popular conhecido como "Cabanagem", ocorrido no século XIX, entre 1835 e 1840 (Costa, 2003).

Dentre as principais características dos municípios da região do Baixo Tocantins, destacase a tradição ribeirinha da população local, igualmente traduzida para o plano de sua organização espacial - herança de uma forma dendrítica de rede urbana (Corrêa, 1987) - a despeito de outras formas de circulação que mais recentemente passam a articular essas realidades locais ao restante da região.

Para a realidade do Baixo Tocantins, uma sub-região tradicionalmente ribeirinha, afetada apenas indiretamente pelas frentes de expansão econômica que tomaram corpo a partir da década de 1960, parece marcante a presença do modelo de urbanização tradicional, ainda que seja uma região situada entre dois grandes empreendimentos: a Usina Hidrelétrica de Tucuruí (produção e distribuição de energia elétrica) e o Complexo Albras/Alunorte (produção de alumina e alumínio). A título de exemplo, nenhum dos grandes projetos instalados no Pará situa-se na microrregião de Cametá ou mesmo na mesorregião do Nordeste Paraense. 
Este mapa do Projeto Grande Carajás, extraído do livro "Guerra dos Mapas", do antropólogo Alfredo Wagner B. de Almeida (1995), mostra a região do Baixo Tocantins, tendo como marcos no norte o Lago de Tucuruí e ao sul a cidade de Belém, sendo que a sede urbana do município de Cametá, locus desta pesquisa, fica na margem esquerda do rio Tocantins.

Figura 1 - Mapa do Projeto Grande Carajás, incluindo a região do Baixo Tocantins.

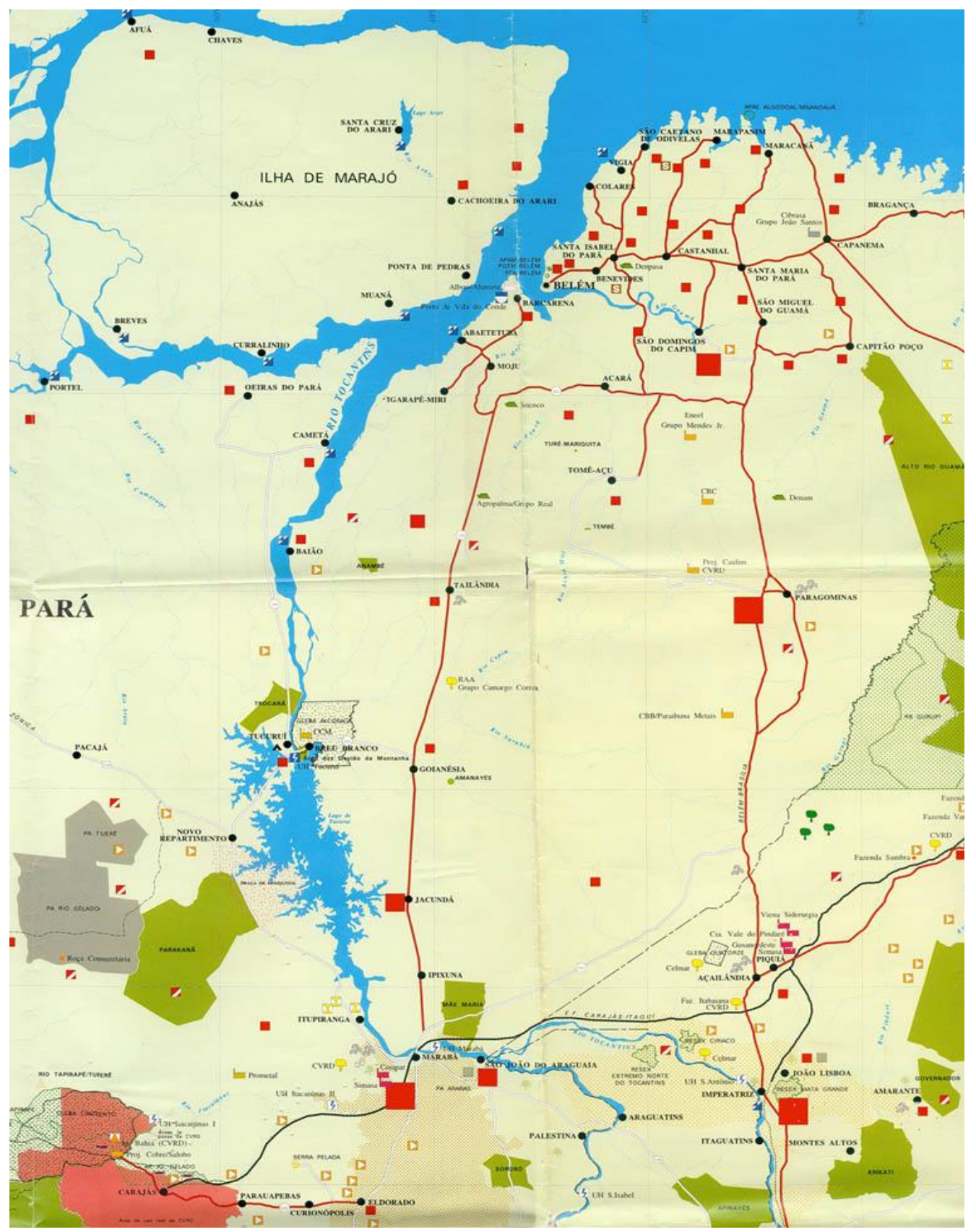

Fonte: Almeida (1995). 
Até o início do século XX, Cametá era a segunda cidade na hierarquia urbana do estado do Pará (depois da capital, Belém). Desempenhava papel de destaque como entreposto da ampla rede de comercialização (e aviamento) estabelecida no período áureo da economia da borracha, ocorrido entre a segunda metade do século XIX e início do século XX. No entanto, após a debacle produtiva na extração do látex, em 1914, a economia de Cametá e da região do Baixo Tocantins entrou em acentuado declínio.

A implantação da UHE Tucuruí, em meados da década de 1980, agrava a estagnação econômica da região, devido, em grande parte, aos efeitos sobre a economia ribeirinha, especialmente sobre a atividade pesqueira.

A mudança no ciclo hidrológico do rio Tocantins, a formação da barragem e do imenso lago de Tucuruí, assim como alterações na fauna e flora aquáticas afetaram o processo de reprodução e de mobilidade de diversas espécies de pescado. Isso influenciou diretamente a oferta de pescado a jusante da UHE Tucuruí, ou seja, na região do Baixo Tocantins. Segundo os dados disponíveis, observou-se uma queda de 65\% no volume de pescado comercializado na região ao longo da década de 1980. Apesar de se registrar uma pequena recuperação no final da década de 1980, a produção pesqueira tem oscilado, não obstante ter ocorrido uma pequena ascensão de 1998 para 2000. De fato, desde então, nunca mais se conseguiu atingir o volume de pescado comercializado em 1981, que foi de 1.188 toneladas. Em 2001, estima-se que este volume foi de cerca de 700 toneladas (PPDJUS, 2003). Mesmo considerando que o declínio da produção pesqueira no Baixo Tocantins não pode ser unicamente imputado à barragem de Tucuruí, o fato é que a implantação da hidroelétrica representou um marco para a região, no caso, bastante negativo para a economia ribeirinha da região, particularmente para a pesca artesanal, conforme o diagnóstico do PDJUS:

A UHE Tucuruí foi forjada como parte integrante dos investimentos do II Plano Nacional de Desenvolvimento (PND), durante o período ditatorial (1964-1984), especificamente do Governo do General Ernesto Geisel (1975-1979), concebido como um dos chamados "grandes projetos" implantados na Amazônia Oriental, sobretudo no estado do Pará. Dentre os projetos implantados na Amazônia Oriental nesse período, destacaram-se o Projeto Ferro Carajás, o complexo AlbrásAlunorte (produção de alumina e alumínio) em Barcarena, a produção de bauxita em Oriximiná, entre outros. A UHE Tucuruí, vital para a produção de energia elétrica para tais empreendimentos, é considerada a maior hidrelétrica integralmente brasileira, inaugurada em 1984, com potência inicial de 3.980 megawatts (MW) ${ }^{3}$. Em decorrência da implantação da barragem na altura do médio curso do rio Tocantins, no estado do Pará, foi construído um reservatório de $2.830 \mathrm{~km} 2$ de área, represando

\footnotetext{
${ }^{3}$ Atualmente foi duplicada a produção de energia elétrica em Tucuruí para 8 mil megawatts.
} 
aproximadamente 46 bilhões e 800 milhões de $\mathrm{m}^{3}$ de água, sendo considerado o maior lago artificial do planeta em volume de água (Silva, 2001).

O processo de construção da UHE Tucuruí pode ser considerado um caso-limite da concepção tecnoburocrática e excludente que vigorou em praticamente todas as experiências de políticas regionais para a Amazônia, sobretudo dos governos autoritários durante o regime militar. A sua construção provocou impactos ecológicos, sociais, econômicos e étnicos que ainda não foram suficientemente avaliados. A implantação do projeto atingiu vários povoados e vilas de cultura ribeirinha ${ }^{4}$, inundou nove reservas indígenas pertencentes a cinco tribos diferentes ${ }^{5}$. Ficaram submersos $170 \mathrm{~km}$ de rodovia federal e a grande parte da biomassa que se encontrava na área inundada não foi retirada, gerando sérios impactos aos ecossistemas e às condições de salubridade locais ${ }^{6}$. As estimativas sobre a população afetada variam entre 25.000 a 55.000 pessoas (Castro, 1989). Além disso, os Grandes Projetos funcionam como enclaves, que canalizam para o exterior (da região ou do país) os impulsos dinâmicos advindos da sua implantação (Vainer \& Araújo, 1992).

\section{Diagnóstico dos Acordos de Pesca na região do Baixo Tocantins}

A implementação de Acordos de Pesca na região do Baixo Tocantins decorre principalmente da crise histórica pela qual passa a pesca artesanal desde a década de 1980, devido aos impactos ambientais decorrentes da implantação da UHE Tucuruí em 1984 e práticas de sobrepesca, com adoção indiscriminada de práticas e artefatos de pesca considerados predatórios, segundo depoimentos de pescadores da região. Até então, a pesca era uma das principais atividades de sustentação das famílias ribeirinhas. Com a crise da economia ribeirinha, a pesca se torna uma atividade mais voltada à subsistência ou ao consumo das famílias (Costa, 2003).

No caso do município de Cametá, a primeira experiência relatada de acordos de pesca (ou de preservação, como também são conhecidos localmente) ocorreu em 1985, na comunidade de Paruru, de Janua-Coelis (Brasil, 2005). A partir das décadas de 1990 e 2000 houve uma proliferação dos Acordos de Pesca, estabelecidos em reuniões comunitárias com a

4 Os povoados e vilas atingidas foram: Breu Branco, Repartimento, Remansão do Centro, Remansão da Beira, Arejão, Jatobal, Chiqueirão, Coari, Canoal, Vila Beta, Vila Braba, Ipixuna, Santa Tereza do Tauri - e mais as cidades de Jacundá e parte dos municípios de Tucuruí, Itupiranga e Nova Jacundá (CMB, 2000).

${ }^{5}$ As tribos indígenas atingidas foram: Assurini, Gavião, Suruí, Parakanã e Xicrin.

${ }^{6}$ A área do lago foi afetada particularmente pela proliferação de vetores de doenças e contaminação por mercúrio. A proliferação de mosquitos e moscas hematófogas resulta, em algumas áreas, na disseminação de "pragas", que inviabilizam a permanência de seus habitantes e limitam as atividades agrícolas e econômicas na área. 
participação da comunidade, nas quais os pescadores e produtores ribeirinhos estabelecem um conjunto de regras definindo o acesso e o uso dos recursos pesqueiros.

Os "acordos de pesca" podem ser definidos como arranjos participativos locais, em que as comunidades ribeirinhas tencionam regulamentar os recursos pesqueiros e restringir as formas de captura consideradas predatórias em regiões de várzea da Amazônia. A iniciativa e execução dos acordos são dos próprios moradores e pescadores das localidades ribeirinhas. Os acordos de pesca podem incluir vários instrumentos de controle da atividade, entre os quais:

(1) a proibição ou limitação do uso de aparelhos de pesca como malhadeira, lanterna de carbureto, tamanho de malhas etc., além de práticas que possam prejudicar o meio ambiente;

(2) proibição da pesca em períodos conhecidos como "defeso", durante a fase de reprodução de determinadas espécies de pescado como tambaqui, pacu, curimatã, branquinha, aracu, piratinga e mapará;

(3) pode-se limitar a quantidade de pescado capturado por viagem;

(4) pode-se proibir a pesca em áreas onde os peixes se reproduzem para povoar outras áreas (rios, lagos etc.), reservando essas áreas para servir de criadouro natural.

É interessante observar que, mesmo com a depreciação da pesca artesanal como meio de sustentação econômica de famílias ribeirinhas do Baixo Tocantins, a pesca (ou a várzea) continua a ser um importante referencial cultural e simbólico dessas comunidades. Um exemplo é a organização social e sindical dessas populações, onde a maioria aparece associada às Colônias de Pescadores, em detrimento dos Sindicatos de Trabalhadores Rurais (STRs). O peso social e político maior da Colônia de Pescadores pode ser explicado pela tradicional identificação dos camponeses ribeirinhos como "pescadores", ao invés de "trabalhadores rurais". Nessa região, para o senso comum, trabalhador rural significa o camponês trabalhador residente na região de "terra firme", no "centro", enquanto os que habitam a região das ilhas e várzeas se auto referenciam como "ribeirinhos" ou "caboclos" (ou "cabôco", conforme o vocabulário local), ou moradores do "sítio" (Costa, 2003).

Historicamente, a conquista da Colônia de Pescadores Z-16, em Cametá, por parte dos pescadores e ribeirinhos, está diretamente relacionada às atividades da Igreja Católica, com 0 apoio importante da Prelazia de Cametá. Esse processo teve início na década de 1980, através das Comunidades Eclesiais de Base, e, mais tarde, com a formação da Pastoral da Pesca, partindo de um trabalho de "conscientização" dos pescadores e de organização política destes segmentos 
sociais. O objetivo era minar a dependência dos pescadores e ribeirinhos em relação aos grupos oligárquicos locais, mais conhecidos como "patrões" do aviamento7.

As bases organizativas e institucionais dos pescadores e ribeirinhos - como as Colônias de Pescadores e outras organizações locais de produtores - se constituem em importantes instrumentos para a discussão e implementação de ações e projetos que visem superar a crise histórica pela qual passa a pesca artesanal no Baixo Tocantins. Entre as alternativas apoiadas pelas Colônias nesse campo, podem-se destacar especialmente duas: a piscicultura e os chamados "acordos de pesca".

No bojo da pesquisa que resultou nesse artigo foram realizadas entrevistas de profundidade, semiestruturadas, com pescadores, moradores e lideranças de três comunidades ribeirinhas de Cametá: Jaracuera Grande, Cuxipiari Carmo e Pacuí de Cima. As entrevistas foram realizadas durante uma viagem de campo realizada em julho de 2005, utilizando uma embarcação a serviço da Colônia de Pescadores Z-16, de Cametá. E foram complementadas por outras entrevistas realizadas em julho de 2013. A seleção dessas localidades foi feita com base na hipótese inicial adotada na pesquisa, que é a de que as iniciativas consideradas exitosas em termos de acordos de pesca possuem relação direta com as trajetórias de evolução institucional (path dependency) e territorial das comunidades ribeirinhas pesquisadas.

A comunidade ribeirinha da ilha de Cuxipiari Carmo se distingue pela forte tradição organizacional, que serviu de base na formação de diversas lideranças ribeirinhas, algumas das quais assumiram funções na direção da Colônia de Pescadores Z-16. Em contrapartida, a comunidade de Jaracuera Grande não possuía tradição no aspecto de organização social - sequer havia um centro comunitário na ilha, até a adoção do acordo de pesca, pelos moradores. Surpreendentemente, esta comunidade tem se destacado pelos avanços introduzidos nas práticas de acordos de pesca, incluindo a adoção de inovações técnicas. Por sua vez, a comunidade de Pacuí apresenta nível intermediário de organização institucional. Contudo, seus moradores desenvolvem ações proativas que garantem a efetivação dos acordos firmados.

Pode-se notar que, de modo geral, a formação política de lideranças locais e dos comunitários na região do Baixo Tocantins foi bastante influenciada pela ação da Igreja Católica, especialmente por meio das Comunidades Eclesiais de Base (CEBs) e da Pastoral da Pesca. A importância da mediação da Igreja Católica e de outras religiões consideradas cristãs, inclusive as

\footnotetext{
${ }^{7}$ No sistema de aviamento, que é um sistema de comércio tradicional em áreas ribeirinhas da Amazônia, o produtor extrativista entrega ao aviador (comerciante) a sua produção, para poder pagar a dívida contraída devido à compra antecipada de gêneros alimentícios e outras mercadorias que o comerciante lhe havia "fiado". É um sistema de "crédito sem dinheiro", no qual o produtor extrativista se vê cada vez mais endividado.
} 
evangélicas, para o fortalecimento de organizações comunitárias e dos mecanismos de formação e conscientização política de famílias ribeirinhas das ilhas e várzeas de Cametá foi atestada pelos depoimentos e entrevistas junto aos moradores e lideranças das comunidades ribeirinhas pesquisadas ao longo deste estudo.

De certa forma, há muitas semelhanças entre as trajetórias político-institucionais das comunidades de Pacuí de Cima com a de Cuxipiari Carmo. A comunidade ribeirinha de Cuxipiari Carmo seria composta por 152 famílias, segundo determinada liderança comunitária, embora 0 registro ou estimativa da Colônia Z-16 seja de que 110 famílias participavam do acordo de pesca na localidade em 2005.

Diferentemente do que se observou em Pacuí de Cima, no caso de Cuxipiari Carmo constituiu-se uma associação com a finalidade específica de gerir o acordo de pesca. Segundo determinado dirigente, a origem do acordo de pesca em Cuxupiari do Carmo está relacionada à percepção em 1997, por parte dos pescadores ribeirinhos, de que o pescado estava diminuindo. Os resultados do acordo de pesca em Cuxipiari Carmo são bastante positivos, na avaliação desse dirigente comunitário, pois "já se pode pescar o mapará".

A capacidade organizativa e institucional das localidades ribeirinhas pode ser considerada, portanto, como uma espécie de "regra geral" para os casos bem sucedidos de acordos de pesca na região do Baixo Tocantins. No entanto, como qualquer regra, esta também comporta as suas exceções. Desta forma, também existem casos considerados bem sucedidos de acordos de pesca onde não havia experiência organizativa acumulada, como no caso da localidade de Jaracuera Grande, no norte do município de Cametá, onde antes sequer havia um centro comunitário.

Do mesmo modo há casos de localidades que, não obstante as suas trajetórias socioinstitucionais e organizativas significativas, não conseguiram sustentar os acordos de pesca, como no caso das localidades de Guajará e Tentem, ambas em Cametá.

Com relação ao processo de implantação do acordo de pesca em Jaracuera Grande, dois aspectos são relevantes. Um deles é a proximidade com experiências exitosas e pioneiras de acordos de pesca; e o outro aspecto se refere à mediação por parte da Colônia de Pescadores Z16. 
Figura 2 - Imagem parcial do município de Cametá (PA), com destaque (em vermelho) para a área do Acordo de Pesca de Jaracuera Grande8.

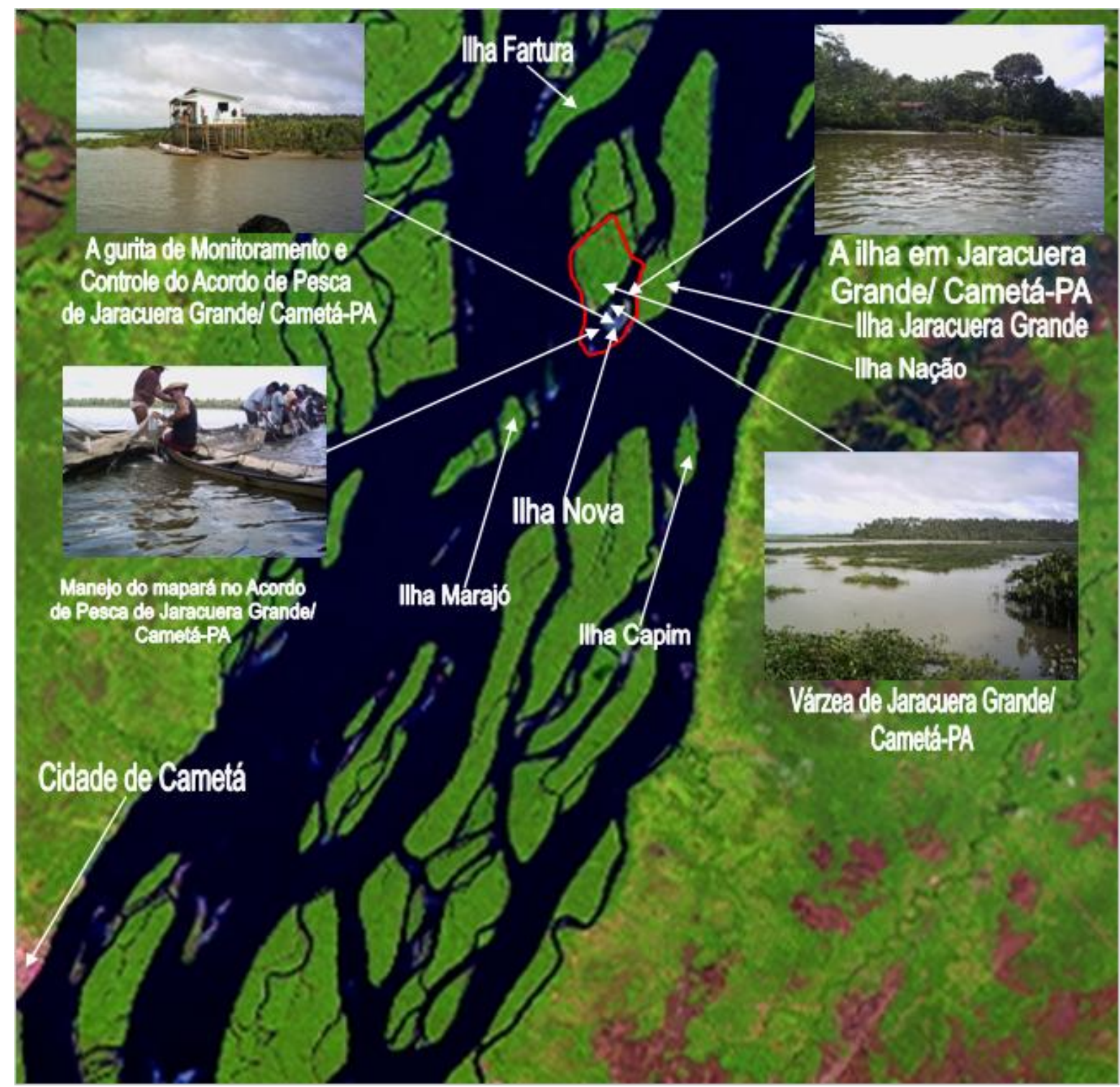

Fonte: Sistema de Informação Geográfica, Ambiental e Social (SIGAS)/IBAMA, 2005.

Sobre o primeiro aspecto, os depoimentos colhidos em Jaracuera Grande revelam a importância da "proximidade geográfica", ou seja, o contato com as experiências exitosas próximas, como o caso de Limoeiro do Ajuru, município vizinho a Cametá, cujas experiências de

\footnotetext{
${ }^{8}$ Este Acordo refere-se à área localizada na bacia hidrográfica do rio Tocantins, no município de Cametá, microrregião de Cametá, no estado do Pará. O Ponto de Referência deste Acordo de Pesca está na coordenada geográfica: PTR-S02 $04^{\prime} 28,3^{\prime \prime}$ e e W049²0'44,3'”: estão inclusos nesta área parte da ilha Jaracuera Grande, parte da ilha Jaracuezinho e mais os corpos d'água que as cercam, coexistindo no local 1 igarapé, 6 furos e 4 enseadas. A área abriga uma biodiversidade de fauna aquática e terrestre, sobressaindo o camarão e o peixe; a vegetação é característica de várzea, destacando-se o açaizeiro. A principal organização social é comunitária, contando com a Associação dos Produtores Familiares de Jaracuera Grande (ACORDAR), constituída por 36 famílias, com sete filhos por família, em média (IBAMA, 2005).
} 
acordos de pesca antecedem as de Cametá, servindo de certa forma, como paradigma. No caso da Colônia de Pescadores Z-16 revela-se a importância da "proximidade organizativa ou social", pois a mediação e o papel político da Colônia foram tanto no sentido de apresentar outras experiências de acordos de pesca quanto no sentido de fornecer assistência e apoio técnico e político. E isso causou um movimento sinérgico, que ajudou a legitimar a presença da Colônia junto aos ribeirinhos e pescadores (inclusive com a formação de duas coordenações de base na ilha), como também ajudou a fortalecer e difundir as práticas dos acordos de pesca, sobretudo da associação encarregada de organizar o acordo de pesca, conhecida como ACORDAR.

No entanto, há outro fator que mobiliza fortemente a comunidade ribeirinha em Jaracuera Grande em torno das práticas do acordo de pesca: o acesso à pesca e ao consumo do "mapará" (Hypophytamus marginatus), o peixe mais apreciado pelas famílias ribeirinhas da região do Baixo Tocantins. De fato, o enfoque principal do acordo de pesca nessa localidade parece ser a pesca do mapará, sobretudo o manejo dos "poços" de mapará, importante fonte de renda e de proteínas para a comunidade e famílias ribeirinhas de Jaracuera Grande (Bordalo \& Cruz, 2011).

Os mecanismos de coordenação econômica podem inclusive ser evidenciados na pesca e no consumo do "mapará" (Hypophytamus marginatus) por parte das famílias ribeirinhas. 0 mapará é um peixe migrador, que se desloca em cardumes, e a sua captura é realizada através da pesca em grupo, conhecida como "pesca de bloqueio" (ou "borqueio", conforme a fala local), mobilizando cerca de 50 (cinquenta) pescadores. 0 produto destas pescarias é compartilhado com o restante da comunidade, fazendo com que a pesca e o consumo do mapará se configurem como uma verdadeira congregação entre as famílias ribeirinhas.

Figura 3 - Pesca de bloqueio do mapará em Jaracuera Grande, na "abertura da pesca", em 01/03/2005.

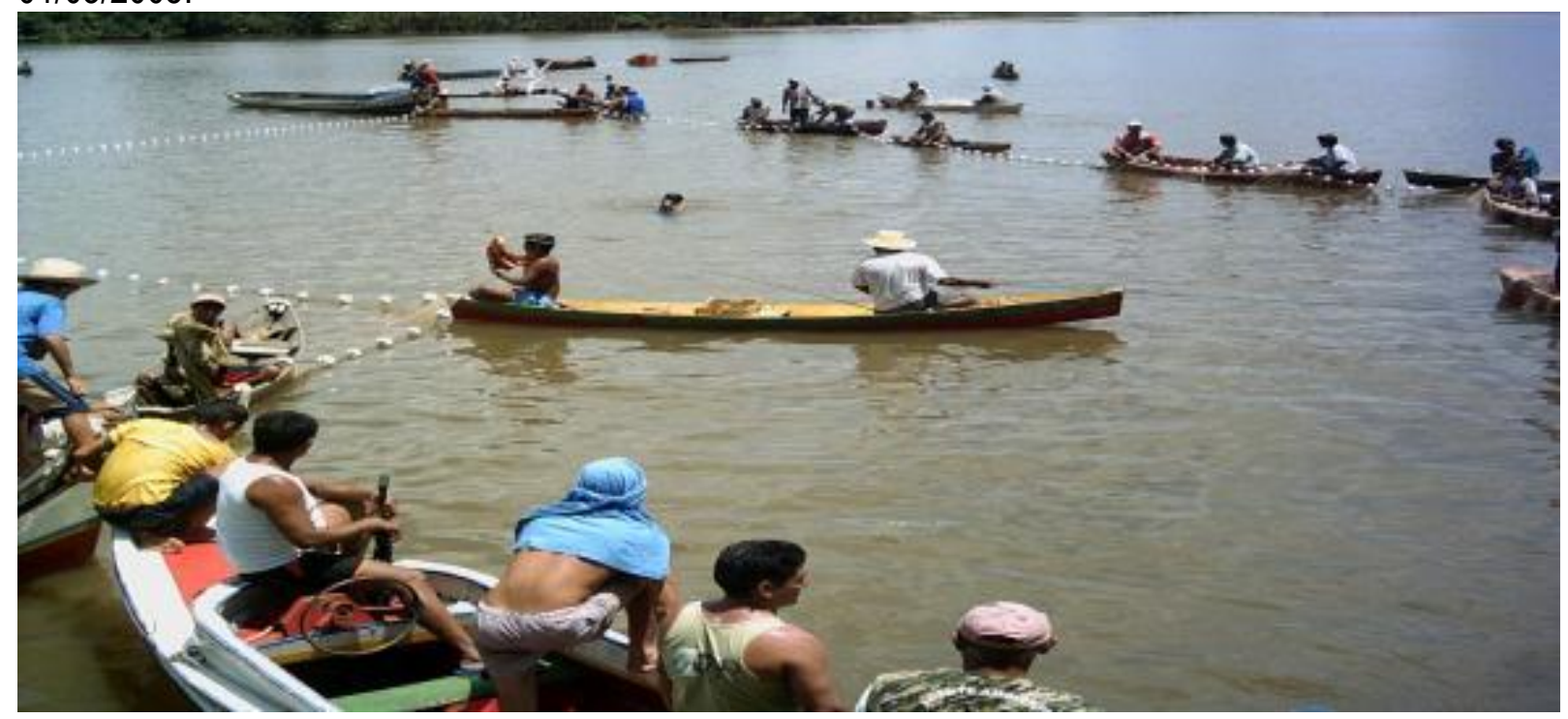

Fonte: Arquivos da Associação ACORDAR, 2005. 
Dessa forma, a realização da pesca do mapará em grupos, assim como o compartilhamento da produção e o consumo entre as famílias locais (mesmo para as que não participam da pescaria e do acordo de pesca) devem-se à capacidade organizativa e institucional dessa comunidade e, sobretudo, pela experiência exitosa do acordo de pesca. Em Jaracuera Grande, foi instituída a Casa do Acordo de Pesca, utilizada como observatório para rastrear o movimento dos cardumes de mapará, mas também tem outros usos sociais. Trata-se de um equipamento social da comunidade, que serve como sala de aula, posto de vacinação, espaço de trabalho em grupo (por exemplo, confecção do "matapi" - apetrecho utilizado na pesca do camarão), reuniões comunitárias (inclusive da associação de produtores e do grupo do acordo de pesca), entre outras funções. A iniciativa de criação da Casa do Acordo de Pesca é, inclusive, um dos benefícios gerados pelas regras e normas compartilhadas do acordo de pesca, conforme o relato de uma liderança comunitária local.

A satisfação do consumo alimentar das famílias ribeirinhas torna-se, portanto, um dos fatores de maior relevância para a indução das práticas dos acordos de pesca. Trata-se de um fator de natureza sociocultural, enraizado em uma tradição alimentar dos ribeirinhos, e que remete à reflexão de Milani (2003), quando diz que o desenvolvimento local não é apenas uma estratégia voltada à integração com o mercado. A cooperação entre os pescadores na atividade produtiva da pesca do mapará em grupos e, sobretudo, o compartilhamento da pescaria com todas as famílias da comunidade, além dos elos de solidariedade social, fortalecem a confiança e os mecanismos de coordenação econômica entre os ribeirinhos, assim como vínculos de capital social (bonding) no interior da comunidade. Assim, pode-se afirmar que a difusão dos acordos de pesca adquire uma maior motivação na "satisfação" pela busca de um melhor padrão de consumo alimentar e de qualidade de vida por parte das famílias ribeirinhas, especialmente com 0 acesso ao consumo do almejado mapará (Santos, 2007).

\section{Considerações finais}

A hipótese base desta pesquisa, que articula a trajetória político-institucional das comunidades ribeirinhas com casos bem-sucedidos de gestão dos acordos de pesca, foi comprovada em pelo menos duas das três comunidades ribeirinhas selecionadas para esta pesquisa. De fato, a comunidade de Cuxipiari Carmo se destacava tanto pela formação de lideranças ribeirinhas como pela implantação de uma associação em 1997 para gerir o acordo de pesca. De forma semelhante, mas com destaque menor, a comunidade de Pacuí de Cima também se destacava pela formação de lideranças ribeirinhas, mas sem ter conseguido até 2005 consolidar ou regulamentar uma associação para gerir o acordo. Por outro lado, a taxa de adesão da comunidade ao acordo de pesca em Cuxipiari Carmo (em torno de $72 \%$ ) é superior a de Pacuí de 
Cima (em torno de 66\%), além do que os relatos corroboram o desempenho superior de Cuxipiari, tanto em termos institucionais quanto na gestão do acordo de pesca.

No entanto, como qualquer regra, esta também tem suas exceções. Desta forma, também existem casos considerados bem-sucedidos de acordos de pesca onde não havia experiência organizativa consolidada, como no caso da terceira localidade ribeirinha pesquisada, Jaracuera Grande, localizada ao norte do município de Cametá, onde antes da implantação do acordo de pesca em 2001, sequer havia um centro comunitário.

Destarte, os resultados deste levantamento demonstraram que uma das principais motivações para que as famílias ribeirinhas decidissem pela implementação e difusão dos acordos de pesca advinha, sobretudo, do ambiente sociocultural. Ou seja, revelou-se uma forte preocupação dos pescadores e das famílias ribeirinhas em melhorar a sua qualidade de vida e padrão de consumo familiar, com acesso ao peixe mais popular da região, o "mapará" (Hypophytamus marginatus), cujo consumo é associado ao açaí (Euterpe oleracea), que atualmente é a base da economia ribeirinha. A relevância desse fator nos casos bem sucedidos dos Acordos de Pesca na região do Baixo Tocantins (sobretudo nas comunidades ribeirinhas de Cametá) revela a importância de fatores históricos e culturais (nesse caso, sobretudo da cultura alimentar) como elemento motivador para experiências partilhadas na gestão comunitária e territorial dos recursos naturais e econômicos.

Além disso, a pesca do mapará, também conhecida como "bloqueio" ou "borqueio", conforme o linguajar peculiar da região, ilustra bem como funciona a gestão das regras do Acordo de Pesca, que envolve um conjunto de ações coordenadas entre os moradores e pescadores locais. As práticas de pesca, incluindo o uso de apetrechos e equipamentos, sofrem uma forte influência dessas regras. Sobretudo no caso das práticas coletivas de pesca, como no caso da captura do mapará, que é um peixe que circula em grupos, em cardumes, e a sua incidência no baixo curso do Tocantins é um fato cada vez mais raro depois da construção da barragem de Tucuruí. Assim, a sua pesca envolve esforços conjuntos de vários grupos de pescadores.

Por outro lado, as práticas dos acordos de pesca podem ser lidas como redes institucionalizadas, que têm como base as redes informais, sobretudo familiares, que entrelaçam as famílias ribeirinhas. Um dos esteios dessas redes são as tradições culturais compartilhadas, sobretudo as que remontam às tradições culturais ribeirinhas, assim como a opção por crenças religiosas comuns, sobretudo cristãs, com destaque para a força das comunidades católicas ribeirinhas, organizadas pelas CEBs, ligadas à Igreja Católica. Essas redes se fortalecem à medida que as relações de confiança se sedimentam, ampliando os estoques e os recursos de capital social, sobretudo o bonding ou comunitário. Por outro lado, os acordos de pesca também podem 
ser interpretados como formas intermediárias de coordenação econômica, tal como formulado por Muls (2008). Isso faz todo o sentido, em especial se a região do Baixo Tocantins for analisada como um território.

Sobre os conflitos existentes nas áreas onde foram implementados os acordos de pesca, destacam-se duas vias principais de conflito: (1) entre os moradores e pescadores residentes na mesma comunidade ribeirinha; e (2) os que opõem os chamados "pescadores de fora" aos que vivem nas comunidades onde vigoram os acordos de pesca. As divergências internas entre os próprios moradores e pescadores ribeirinhos - surgem, sobretudo, na etapa inicial dos acordos, quando se impõe um dilema ou um trade off para as famílias ribeirinhas, tal como se costuma analisar na literatura econômica. Se por um lado, a decisão em participar dos acordos de pesca significa a busca de satisfação do consumo familiar por meio do acesso ao almejado mapará e outros peixes, essa opção significa, por outro lado, a renúncia à pesca e ao consumo imediato. Dessa forma, na etapa inicial dos acordos de pesca as famílias ribeirinhas têm de renunciar ao consumo e à captura mais imediata do pescado, evitando, portanto, as práticas de pesca predatória, o que se torna uma decisão muito difícil, visto que essas famílias se encontram em um contexto de crise prolongada da pesca na região do Baixo Tocantins.

O que estimula as famílias a persistir na regulamentação dos recursos pesqueiros por meio dos acordos de pesca são principalmente as experiências coletivas da pesca de bloqueio, notadamente do mapará, que envolve o compartilhamento e as relações solidárias na partilha do produto das pescarias. Isto é particularmente importante nas comunidades ribeirinhas onde se localizam "poços de criação", e que se destacam na pesca do mapará, como no caso de Jaracuera Grande. Em outros casos, as relações sociais de confiança e de identidade cultural e territorial entre as famílias e os produtores ribeirinhos conseguem transcender as motivações mais mesquinhas e as estratégias de ordem individual ou oportunistas, segundo a análise de Ostrom (2008).

No caso dos conflitos com os "pescadores de fora", estes são mais frequentes e refletem o dilema de que os territórios da pesca também são de uso comum. Portanto, a sobreposição de "territórios de pesca" envolvendo diversos grupos e pescadores e, sobretudo, contrapondo os pescadores das comunidades que praticam os acordos de pesca frente aos chamados "pescadores de fora", gera sérios conflitos. Esses conflitos inclusive estão na base de vários acordos de pesca, em geral, dos primeiros. A ação dos agentes ambientais voluntários torna-se importante para a fiscalização e a tentativa de persuadir os pescadores que infrigem as normas dos acordos. Entretanto, esses agentes voluntários, que são pessoas da própria comunidade e que recebem treinamento do IBAMA, não possuem poder punitivo e de sanção, que é de 
responsabilidade do IBAMA e de seus fiscais, e isso se torna uma limitação das suas atividades. Porém, em alguns casos, a gestão compartilhada dos acordos adquire uma legitimidade tão grande que o IBAMA concede autorização para a apreensão dos apetrechos de pescadores que são flagrados infringindo as normas do acordo de pesca. Nesses casos, o agente voluntário emite a notificação da infração através do auto de constatação, que será posteriormente encaminhado ao IBAMA, juntamente com o material apreendido (BORDALO; CRUZ, 2011).

Isso reflete, por outro lado, as limitações do apoio do IBAMA, que não possui equipamentos e fiscais suficientes para cobrir toda a área de jurisprudência do escritório regional do IBAMA em Cametá, pois são apenas três fiscais, que devem cobrir sete municípios com enormes extensões territoriais, sobretudo as ilhas e áreas de várzea. Isso também reflete a insegurança jurídica dos acordos de pesca em Cametá e em toda a região do Baixo Tocantins, pois, até então o IBAMA não emitiu nenhuma portaria de reconhecimento de qualquer acordo de pesca existente na região.

O fato dos resultados das pescarias coletivas serem partilhados por todas as famílias da comunidade, mesmo as que não participam do acordo de pesca, permite afirmar que a difusão dos acordos de pesca adquire uma maior motivação na "satisfação familiar", pela busca de um melhor padrão de consumo alimentar e de qualidade de vida por parte das famílias ribeirinhas. Sem dúvida, este é um traço fundamental que difere as experiências dos acordos de pesca de outras iniciativas de desenvolvimento endógeno, que muitas vezes parecem atreladas a objetivos de uma maior inserção na economia globalizada e na conquista de novos nacos de mercados internacionais.

\section{Referências bibliográficas}

ACORDAR. Fotos dos arquivos da Associação ACORDAR. Cametá: ACORDAR, 2005.

ALMEIDA, Alfredo Wagner B.. de. Carajás: a guerra dos mapas. 2. ed. Belém: Supercores, 1995. BORDALO, Carlos Alexandre Leão; CRUZ, Mariana Neves (. Territorialidade e gestão de recursos de uso comum no Baixo Tocantins: o caso dos acordos de pesca em Jaracuera Grande - Cametá, PA. In: SILVA, João Marcio Palheta da; SILVA, Christian Nunes da (Org.). Pesca e territorialidade: contribuições para a análise espacial da atividade pesqueira. Belém:

GAPTA/UFPA, 2011.

BRASIL. Ministério do Meio Ambiente. Subprograma Projetos Demonstrativos. Cametá: as experiências nas localidades de Joroca de Baixo e Cuxupiari Carmo. Brasília: MMA/PDA,. (Série Sistematização: comunidades construindo sua sustentabilidade), 2005.

CASTRO, Edna. R.. Resistência dos atingidos pela barragem de Tucuruí e construção de identidade. In: Castro, Edna. R.; Hébette, Jean. (Org.). Na trilha dos grandes projetos. Modernização e conflito na Amazônia. Belém: NAEA/UFPA, 1989.

CORRÊA, Roberto L.. A periodização da rede urbana da Amazônia. Revista Brasileira de Geografia. Rio de Janeiro, v. 4, n. 3, p. 38-68, jul./set, 1987. 
COSTA, Gilson da Silva. Desenvolvimento rural sustentável com base no paradigma da agroecologia: estudo sobre a região das ilhas em Cametá, Pará-Brasil. 2003. 307f. Dissertação (Mestrado em Planejamento do Desenvolvimento) - Núcleo de Altos Estudos Amazônicos, Universidade Federal do Pará, Belém, 2003.

DALLABRIDa, Valdir R.; BECKER, Dinizar F. Dinâmica territorial do desenvolvimento. In: Becker, Dinizar F.; Wittmann, Milton L. Desenvolvimento Regional: abordagens interdisciplinares. 2. ed. Santa Cruz do Sul: EDUNISC, 2008.

IBAMA. Mapa sobre o Acordo de Pesca de Jaracuera Grande - Cametá- PA. Imagem Landsat - Pará Carta: SA-22-Z-B-I-1, articulação compatível com a escala 1:50.000 (IBGE). Cametá: IBAMA, 2005.

MILANI, Carlo. Teorias do Capital Social e Desenvolvimento Local: lições a partir da experiência de Pintadas (Bahia, Brasil). Salvador: UFBA, 2003.

MULS, Leonardo Marco. Desenvolvimento local, espaço e território: o conceito de Capital Social e a importância da formação de Redes entre organismos e instituições locais. Revista Economia, Brasília, v. 1, p. 1-21, jan./abr. 2008.

OSTROM, Elinor. Governing the Commons: the evolution of institutions for collective action. New York: Cambridge University Press, 1990.

OSTROM, Elinor. The meaning of social capital and its link to collective action. In: SVENDSEN, Gert T.; SVENDSEN, Gunnar L. (Eds.). Handbook on Social Capital. Northampton: Edward Elgar. 2008.

PPDJUS-Plano Popular de Desenvolvimento Sustentável da região a Jusante da UHE Tucuruí. Versão preliminar. Belém: Eletronorte; Conselho Gestor PPDJUS, 2003. Mimeografado.

PUTNAM, Robert. Making Democracy Work: Civic Traditions in Modern Italy. Princeton University Press, 1993.

SABOURIN, Eric. Manejo dos recursos comuns e reciprocidade: os aportes de Elinor Ostrom ao debate.

Revista Sustentabilidade em Debate, Brasília v. 1, n. 2, 2010. Disponível em:

<http://periodicos.unb.br/index.php/sust/article/view/1689/1311>. Acesso em: 08/12/2013

SANTOS, Milton; SILVEIRA, Maria Laura. O Brasil: território e sociedade no início do século XXI. 5. ed.

Rio de Janeiro: Record, 2003.

SANTOS, Valcir B. Desenvolvimento sustentável e pesca artesanal na Amazônia Oriental: as dimensões da sustentabilidade dos acordos de pesca na região a jusante da UHE Tucuruí. In: ENCONTRO CIÊNCIAS SOCIAIS E BARRAGENS, 2, 2007, Salvador. Anais... Salvador: EDUFBA, 1 CD-ROM, 2007.

SANTOS, Valcir Bispo. Território e capital social em acordos de pesca no Baixo Tocantins: uma abordagem institucionalista. 2015. 292 f. Tese (Doutorado em Planejamento Urbano e Regional)Instituto de Pesquisa e Planejamento Urbano e Regional, Universidade Federal do Rio de Janeiro, 2015.

SEN, Amartya K. Desenvolvimento como liberdade. São Paulo: Companhia das Letras, 1999.

SILVA, Maria das Graças da. A proposta de criação de Reserva Extrativista na Região do lago da UHE Tucuruí: estratégia de politização ou reorganização territorial? In: Encontro Nacional da Anpur, 9, 2001, Rio de Janeiro. Anais... Rio de Janeiro: ANPUR, v. 3, p. 1218-1227, 2001.

STORPER, Michael. Sociedade, Comunidade y Desarrollo Económico. Cadernos IPPUR, Rio de Janeiro, v. 17, n. 2, p. 7-44, ago./dez., 2003.

VAINER, Carlos B.; ARAUJO, Frederico. G. B. Grandes Projetos hidrelétricos e desenvolvimento regional. Rio de Janeiro: CEDI, 1992.

Recebido em 15 de Janeiro de 2019.

Aceito para Publicação em 25 de Março de 2019. 


\section{RESUMO}

O foco deste artigo é analisar os "acordos de pesca" praticados por comunidades ribeirinhas da Amazônia Oriental, nas ilhas do município de Cametá, na região do Baixo Tocantins - nordeste do estado do Pará, no estuário da bacia do rio Amazonas - tendo em vista, sobretudo, a sua dinâmica interna e os recursos endógenos que articula e mobiliza. Os "acordos de pesca" são arranjos institucionais comunitários praticados por pescadores artesanais de localidades ribeirinhas com a finalidade de manejar recursos pesqueiros, mas que se notabilizam por práticas de mobilização de recursos do capital social. A região do Baixo Tocantins fica a jusante da UHE Tucuruí e a pesca artesanal da região entrou em uma crise prolongada com o barramento do rio Tocantins em meados de 1980. A coordenação das relações sociais e econômicas no âmbito dos acordos de pesca se ancora em redes de pescadores / produtores agroextrativistas e famílias ribeirinhas que partilham uma forte tradição cultural ribeirinha e um sentimento de pertencimento territorial. Há um apoio decisivo de algumas entidades mediadoras, sobretudo das Colônias de Pescadores e das Comunidades Eclesiais de Base (CEBs), mas não se nota apoio efetivo importante por parte do poder público, o que potencializa os conflitos de pescadores e moradores das comunidades ribeirinhas com os chamados "pescadores de fora". Desta forma, pretende-se interpretar os acordos de pesca como práticas de desenvolvimento territorial a partir de uma abordagem situada no campo institucionalista da teoria econômica.

PALAVRAS-CHAVE: Acordo de pesca. Arranjo comunitário institucional. Desenvolvimento territorial. Capital social. Amazônia Oriental.

\section{ABSTRACT}

The focus of this article is to analyze the "fisheries agreements" practiced by coastal communities of Cameta municipality of islands in the Lower Tocantins - northeastern Pará state, in the estuary of the Amazon River basin - with a view, particularly, its internal dynamics and local resources that articulates and mobilizes. The "fisheries agreements" are institutional arrangements practiced by artisanal fishermen of coastal localities in order to manage fisheries resources, but are notable for practical social innovation and resource mobilization of capital. The Lower Tocantins region is downstream of Tucurui Hydroelectric Plant and artisanal fisheries in the region entered a prolonged crisis with the Tocantins river bus in the middle of 1980. The coordination of social and economic relations under fisheries agreements anchors in fishing nets / agroextractivist producers and riverine families who share a strong riverside cultural tradition and a sense of territorial belonging. There is a strong support of some mediating entities, especially the colonies of fishermen and Basic Ecclesial Communities, but does not notice effective support important by the government, which enhances conflicts of fishermen and residents of coastal communities with the so-called "fishing out". Thus, it is intended to interpret the fisheries agreements and territorial development practices from an institutionalist approach situated in the field of economic theory.

KEYWORDS: Fishing Agreement. Small-scale fishing. Community institutional arrangement. Social capital. Territorial development. Region of Lower Tocantins, Eastern Amazon. 